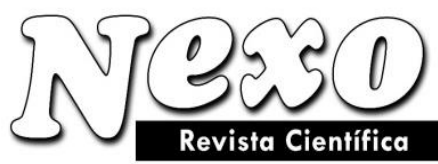

\title{
Basics of systems approach to methodology of assessing waterworks facili- ties on natural environment
}

\section{Fundamentos del enfoque de sistemas para la metodología de evaluación de instalaciones de obras acuáticas en medio natural}

\author{
Vladimir L. Bondarenko, ${ }^{1}$ Elguja D. Khetsuriani, ${ }^{2 *}$ Allaberdy. I. Yliasov, ${ }^{3}$ \\ Elena. A. Semenva, ${ }^{4}$ Valery N. Azarov ${ }^{5}$
}

\footnotetext{
${ }^{1}$ Novocherkassk Engineering And Land Reclamation Institute, Don State Agrarian University. Department of Technosphere safety, land reclamation and environmental management. Novocherkassk, Russia.

${ }^{2}$ Platov South Russian State Polytechnic University (NPI). Department "Water management, engineering networks and environmental protection". Novocherkassk, Russia.

${ }^{3}$ Asian branch of the WTL (United States). Moscow, Russia.

${ }^{4}$ School of Caucasian hospitality of the Pyatigorsk branch of the North Caucasus Federal University. Pyatigorsk, Russia.

${ }^{5}$ Volgograd State Technical University. Department "Life Safety in Construction and Urban Economy". Volgograd, Russia.

*goodga@mail.ru
}

(recibido/received: 28-octubre-2020; aceptado/accepted: 15-enero-2021)

\begin{abstract}
According to the regulatory and environmental requirements on operating waterworks facilities referred to as objects of activity, the environmental influence of these facilities must be assessed in terms of water resource utilization, which is exactly the goal of this study. The basics of the methodology of this assessment are developed by the system approach centred around the notion of System. The results of studying the interaction of the object of activity $(\mathrm{OA})$ with the natural environments (NENV) of the basin geosystem are used in developing the basics of the methodology of environmental influence assessment (EIA). The study results have been used in designing and building hydropower engineering facilities in the North Caucasus in the South of Russia.
\end{abstract}

Key words: waterworks facility, system, methodology, river Cuban

\section{RESUMEN}

De acuerdo con los requisitos reglamentarios y ambientales sobre el funcionamiento de las instalaciones sanitarias denominadas objetos de actividad, se debe evaluar la influencia ambiental de estas instalaciones. en términos de utilización de los recursos hídricos, que es exactamente el objetivo de este estudio. Los fundamentos de la metodología de esta evaluación se desarrollan mediante el enfoque de sistema centrado en la noción de sistema. Los resultados del estudio de la interacción del objeto de actividad (OA) con los ambientes naturales (NENV) del geosistema de cuenca se utilizan en el desarrollo de los fundamentos de la metodología de evaluación de la influencia ambiental (EIA). Los resul- 
tados del estudio se han utilizado para diseñar y construir instalaciones de ingeniería hidroeléctrica en el norte del Cáucaso en el sur de Rusia.

Palabras clave: instalación sanitaria, sistema, metodología, río cubano.

\section{INTRODUCTION}

Modern environmental issues take centre stage in terms of the need for ensuring environmental safety (ENVS) of economic activities related to utilizing water resources. The aim of ensuring the environmental safety of production processes and procedures on irrigated lands, electricity generation at HPP, PSPP, CHPP, and NPP, water supply of urban households, etc. is to conserve natural systems by maintaining their integrity and life-sustaining functions for sustainable social development, improve the quality of living and public health, providing ENVS within the influence domains of waterworks facilities in the the spatial confines of which the qualitative and quantitative parameters of water resources are shaped (Fig. 1).

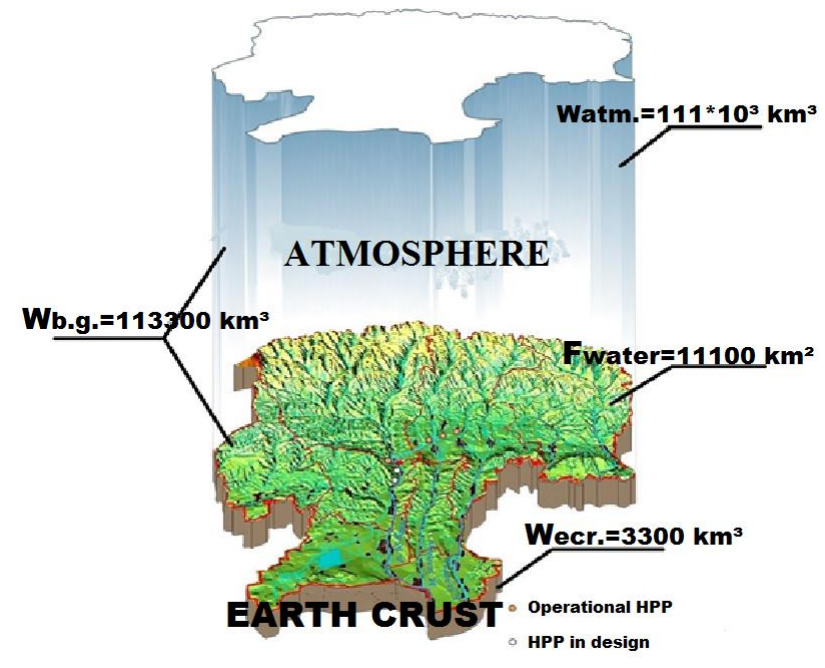

Figure 1. Virtual model of the basin geosystem of the upper Cuban

The relevance of the research aimed at developing the methodology of EIA for OA as part of NENVOA-PPL NES is defined by the need for developing almost all the branches of economic and other activities in which water resources are used. On the other hand, according to research, OA cause certain changes in the natural environments of the basin ecosystem and the formation of environmental state as a major ENVS factor, which stipulates the need for EIA.

Proceeding from the modern environmental requirements on providing environmental safety, the EIA procedure is required for OA related to utilizing water resources in various process systems of water consumption, for example, agricultural production on irrigated lands, systems of multipurpose water supply of urban households, etc., electricity generation at HPP, PSPP, CHPP, and NPP, when the influence domain, in which the OA affects the NENV, covers all of the spatial boundaries of the basin geosystem within which water resources are formed, which makes the necessary research very complex.

The water resources of the Russian Federation consist mainly of the river runoff formed within the country, and only $5 \%$ of the runoff come from the neighbour states. The total amount of water withdrawn in Russia from the natural sources for all economic activity purposes is about

$70.8 \mathrm{bln} \mathrm{m}^{3}$ (2014) and steadily tends to decrease. In terms of the amount of water withdrawn from the natural sources of the basins of such rivers as Cuban, Lower Don, and Terek are Krasnodar krai, Republic of Dagestan, Rostov oblast', and Stavropol krai (6.4, 4, 3.6, and $2.4 \mathrm{bln} \mathrm{m}^{3}$, respectively). 
In Russia the number of already operational and newly built waterworks facilities for utilizing water resources in various branches of economic activity exceeds 65,000 units. The sustainable utilization and consumption of water is ensured by regulating the river runoff within the considered basin geosystems by building water-storage hydro systems with multiyear or seasonal control. The waterworks facilities referred to hereafter as objects of activity (OA) and intended for regulating runoff, withdrawing design amounts of water for consumption $\left(\mathrm{Q}, \mathrm{m}^{3} / \mathrm{s}\right)$ to water consumption systems, and controlling the consumption of water in water resource utilization process flows, play the main functional role as part of the Natural Environment-Object of Activity-Population (NENV-OA-PPL) natural engineering system (NES).

In terms of methodology the natural hierarchical structure of basin geosystems with hydrographic networks of watercourses (big, medium, and small rivers, and springs) formed within their limits is recommended for use depending on the goals of utilizing and consuming water resources and the structural parameters and way of placing the OA in the water withdrawal territory of a fluvial network. Thus the confluents of first-level basin geosystems of such rivers, as Don, Cuban, Terek, etc., define the state of second-level basin geosystems, the spatial confines of second-order confluents define the state of third-level basin geosystems, etc. For example, the spatial limits of the first-level basin geosystem of river Don extend to $4,768,600 \mathrm{~km}^{3}$, including more than 10,000 active small and medium and several tens of large water storages, with the Tsimlyanskoe storage as the largest one of the kind in the South of Russia (its efficient volume is $11.5 \mathrm{~km}^{3}$ ). Henceforth, it is methodologically expedient to consider the basin geosystem, within which water resources are formed and used.

According to the analysis of the experience in utilizing water resources in the water consumption and utilization systems within the confines of the basins of rivers Cuban, Lower Don, and Terek, the more serious is the environmental effect produced by an operational OA, the earlier this effect should be prevented. It can therefore be concluded that the utilization of water resources needs not so much more efficient methods of coping with negative effects as a more efficient methodology of environmental impact assessment (EIA) of operational and newly created OA.

The purposed building of OA within basin geosystems, proceeding from the modern environmental requirements on providing ENVS in OA influence domains is stipulated by conserving a favourable environment for people, plants, and animals, the biological diversity of ichthyofauna (fish species, etc.) and flora in waterworks facilities used as sources of water for irretrievable water consumption systems (urban water supply systems) and returnable water utilization (electricity generation at HPP, PSPP, CHPP, and NPP, etc.). Henceforth, to ensure ENVS there has arisen an urgent need for developing the basics of the EIA methodology as a set of phases, research tools, steps, and procedures, forming the sequence of and conditions for preparing decisions on building OA. The EIA methodology for OA must consider the system principles of interaction and relations among the OA, structural formations, and vital interests of the population (PPL) in OA influence domains.

Proceeding from the general need for utilizing water resources in economic activities, taking account of socioeconomic requirements, EIA is aimed at preparing environmentally valid design permits for building OA, including a set of hydraulic engineering structures, for example, Zelenchukskaya HPPPSPP. The goal is achieved by methodologically solving all the problems with EIA.

The theoretical significance of the NENV-OA-PPL class of NES related to utilizing water resources consists in the fact that the study of this type of systems has rarely received enough attention in Russian and foreign research literature, though the issue with water as a renewable resource is second among the top ten major global issues in the current phase of social development in the NatureSociety-Mankind global system.

The practical significance of creating and developing NENV-OA-PPL NES is defined by the expansion of opportunities for assessing more impartially the influence of OA on the natural environments within the basin geosystem, where water resources are formed, considering the vital needs of local 
population. The system approach to assessing the influence of OA on NENV expands the room for creating ecofriendly design solutions and environmental safety provision technologies.

These studies imply creating and developing the new NENV-OA-PPL class of NES for utilizing water resources in various branches of economic and other activities.

The system approach was used to develop the basics of system-level integrated monitoring (SLIEM) in OA influence domains.

The relevance of the research aimed at creating and developing the EIA methodology for the NENVOA-PPL class of NES is defined by the need for studying the formation of ordered relations among the NENV, OA, and PPL and integrity as a control state for ensuring conservation and development and for maintaining with development the main role of the whole as part of the system, which is achievable by creating the methodology of assessing the influence on OA.

\section{MATERIALS AND METHODS}

The EIA methodology uses the system approach for studying the interaction and relations among the main technogenic component (OA), the components of the NENV, and the vital interests of the local PPL as part of the NENV-OA-PPL NES that functions within the considered basin geosystem. In the system approach this NES is treated as an integrated, dynamic, open, sustainably nonequilibrium system with natural and technogenic structural formations involved in continuous self-organization (Khetsuriani et al., 2019; Bondarenko, et al. 2007, 2009, 2016, 2019; Budyko \& Avakyan, 1977; Mosaferi, Pourakbar, Shakerkhatibi et al 2014; Rezaeinia et al 2018; Aazami, et al., 2015). Hierarchically, basin geosystems of higher levels affect the structural changes in the self-organization of basin geosystems of lower levels. In its respect, the structural formation in basin geosystems of lower levels affects the self-organization of basin geosystems of higher levels. It can therefore be concluded that the main condition of the sustainable performance of the NENV-OA-PPL NES within the confines of the considered basin geosystem is that the NENV-OA-PPL NES must be surrounded by a hierarchically higher NENV that has some influence on the performance of the OA. The analogy between the patterns and principles of interaction and relations among natural basin geosystems of various levels, from local to the Earth's biosphere, the activity of which shows in the OA influence domains within the considered basin geosystem, is methodologically used as a compromise working assumption.

According to the goals and methodology of EIA, its major phases are series of engineering and environmental route surveys, laboratory tests, and office operations within the considered basin geosystem, that are aimed at assessing the environmental position defined following the results of analyzing natural characteristics, including climate; geomorphological features of the OA site; geological structure of the earth crust's upper layers; water resources formed in the water catchment territory of the fluvial network; geohydrological conditions in the influence domain of the reservoir hydrosystem; waterconducting and other types of hydraulic engineering structures; anti-pollution protection of ground water; activity assessment of exogenous geological conditions; soil cover; plants; wildlife; landscape division; specially protected areas; wildlife sanctuaries; reserves; national parks; natural, architectural, and cultural landmarks; recreation resources; socioeconomic conditions. A major factor forming the environmental position within the considered basin geosystem are sources of pollution and the kind of their location in the water catchment area of the basin geosystem. The main sources of polluting the NENV are industrial and agricultural production, transport, domestic and industrial waste, public utilities, recreation, and tourism.

To impartially assess the environmental position of the NENV of the considered basin geosystem, reference points of initial condition are set for each kind of natural medium, including the atmosphere, surface and ground waters, soil cover; these points are accepted according to the results of the engineering environmental, geological, and route surveys conducted in the entire water catchment area of the considered basin geosystem. It is recommended to make the quantitative and qualitative assessment of the kinds of influence of the OA on the NENV for the design (least favourable) environmental 
position, considering all discovered influences and permissible levels of each of them for all lifesupporting environments. The EIA results are used for deciding whether the building and operation of OA can be permitted or not. Note that a factor of major importance is the research team that must include geologists, agrologists, hydraulic engineers, hydrologists, botanists, zoologists, ecologists, etc. This system approach to EIA in the course of design and construction works was tried with sufficient success and then translated into practice in the Stavropol and Krasnodar krai and the Republic of North Ossetia, and Krasnodar krai.

The interaction among the three components of the NENV-OA-PPL NES functional within the considered basin geosystem causes certain effects divided in foreseeable and controllable, foreseeable and uncontrollable, and unforeseeable and uncontrollable.

Foreseeable and controllable effects are the ones that can be predicted in the design phase so as to take respective protective steps.

Foreseeable and uncontrollable effects are the ones that can be predicted in the design phase but the occurrence of which cannot be controlled by the tools and means available at the current stage of scientific and engineering development.

Unforeseeable and uncontrollable effects are the most dangerous ones; they cannot be predicted, and their occurrence cannot be controlled. The environmental position in the NENV of the OA influence domains that stipulates an environmental crisis occurs when adopted design solutions contain few or almost no EIA studies. The results of hydrochemical, lithochemical, and geochemical surveys in the OA influence domains are used to identify the spatial pattern of NENV pollution, including differentiation by environmental hazard rate. The technogenic areolas of the OA defines the extent and morphology of its influence domains. The general pollution pattern in the OA influence domains depends on the spatial relation among the source of pollution and the reciprocal superimposition of technogenic areola loops and the intensity of the matter, energy, and information (MEI) streams flowing from the technogenic component OA as part of the NENV-OA-PPL NES. The geoecological maps of the kind of the OA's influence on the NENV in the influence domains were drawn using the Arc GIS-9 geoinformation system and the Spatial Analist and 3-D Analist modules and are shown in Figures 2, 3, 4. For the integral assessment of the environmental setting in the Upper Cuban basin in the course of building the Zelenchukskaya HPP-PSPP see Figure 5.

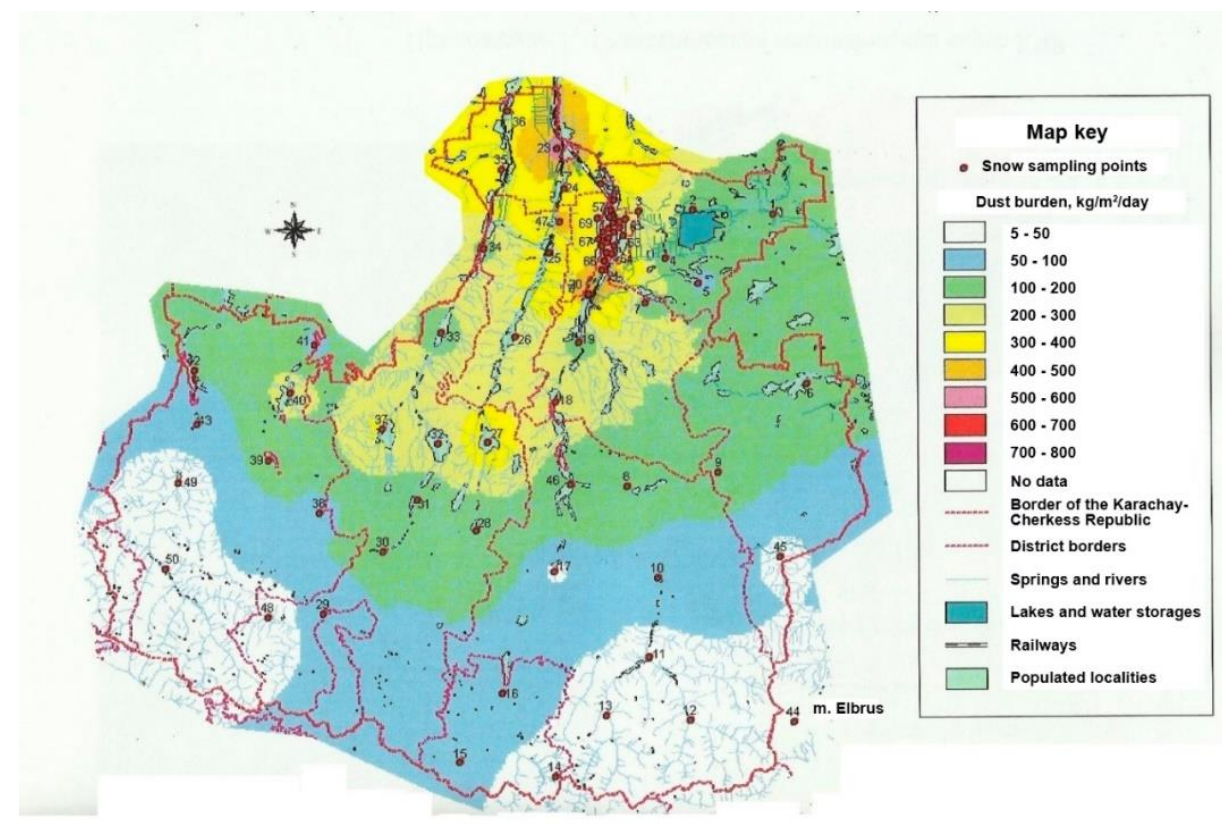

Figure 2. Dust burden on the water catchment territory of the Upper Cuban basin (2005-2015) 


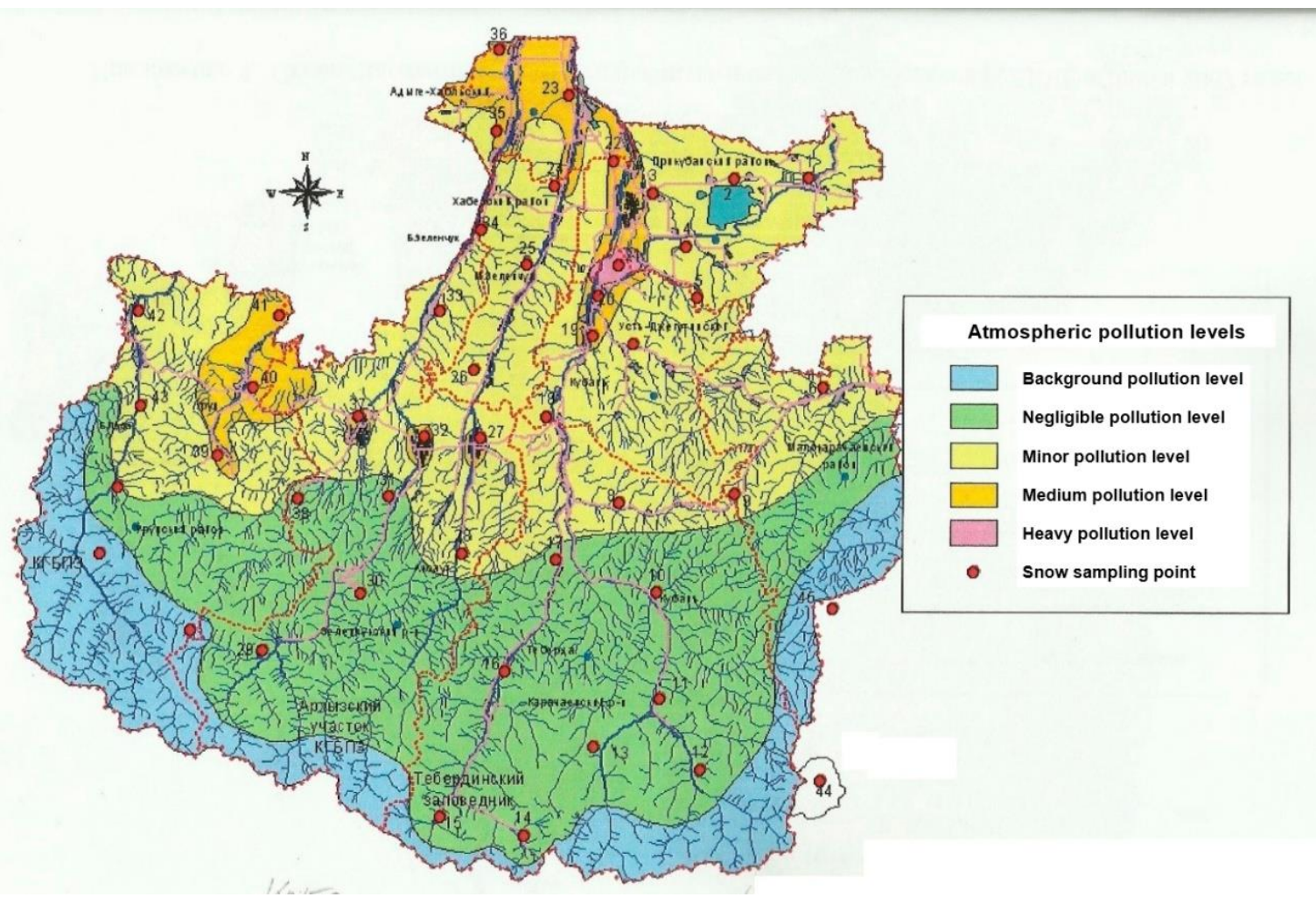

Figure 3. Atmospheric pollution levels in the Upper Cuban basin geosystem

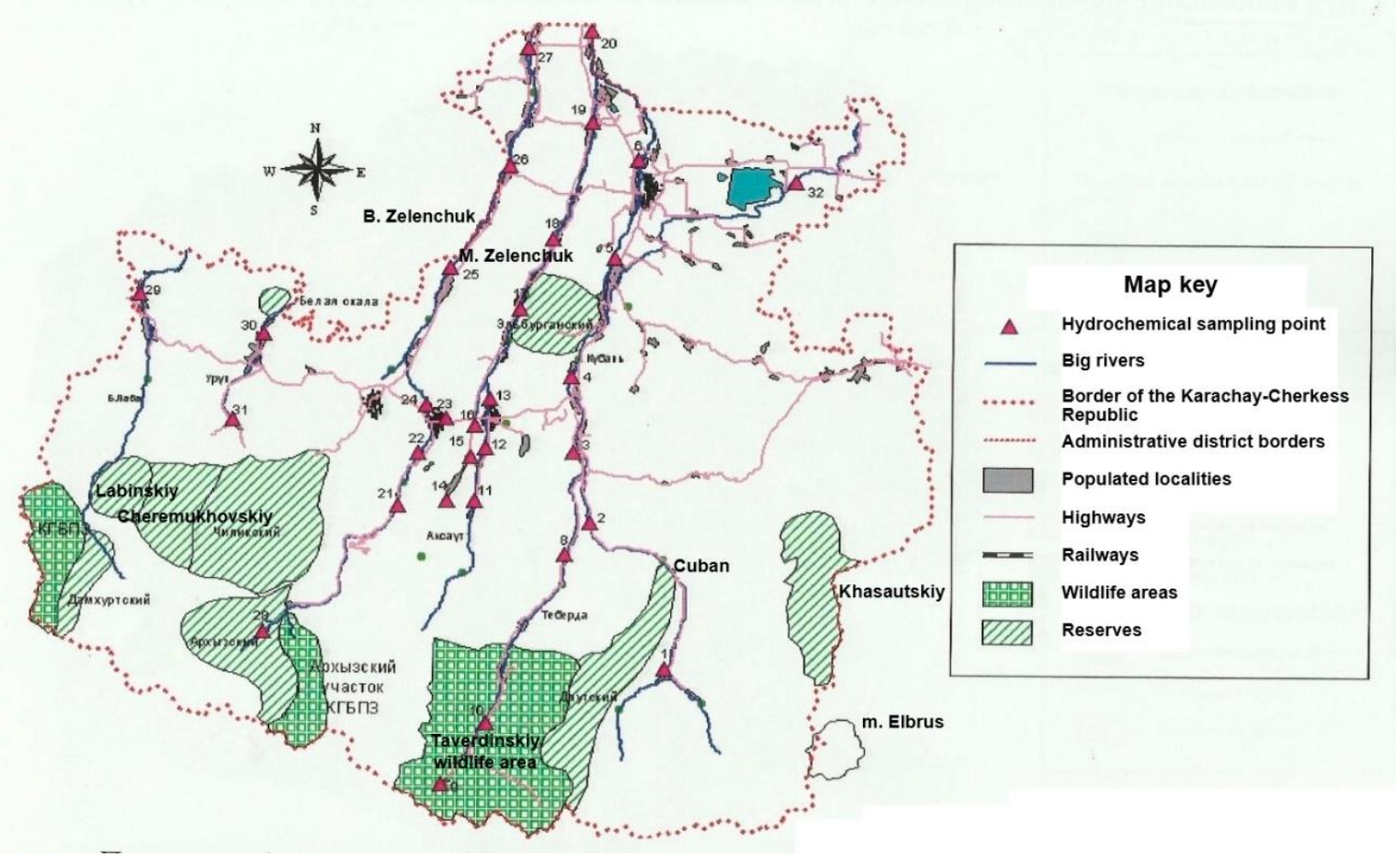

Figure 4. Map of the hydrochemical and hydrobiological appraisal of the fluvial network of the Upper Cuban in 2005-2015 


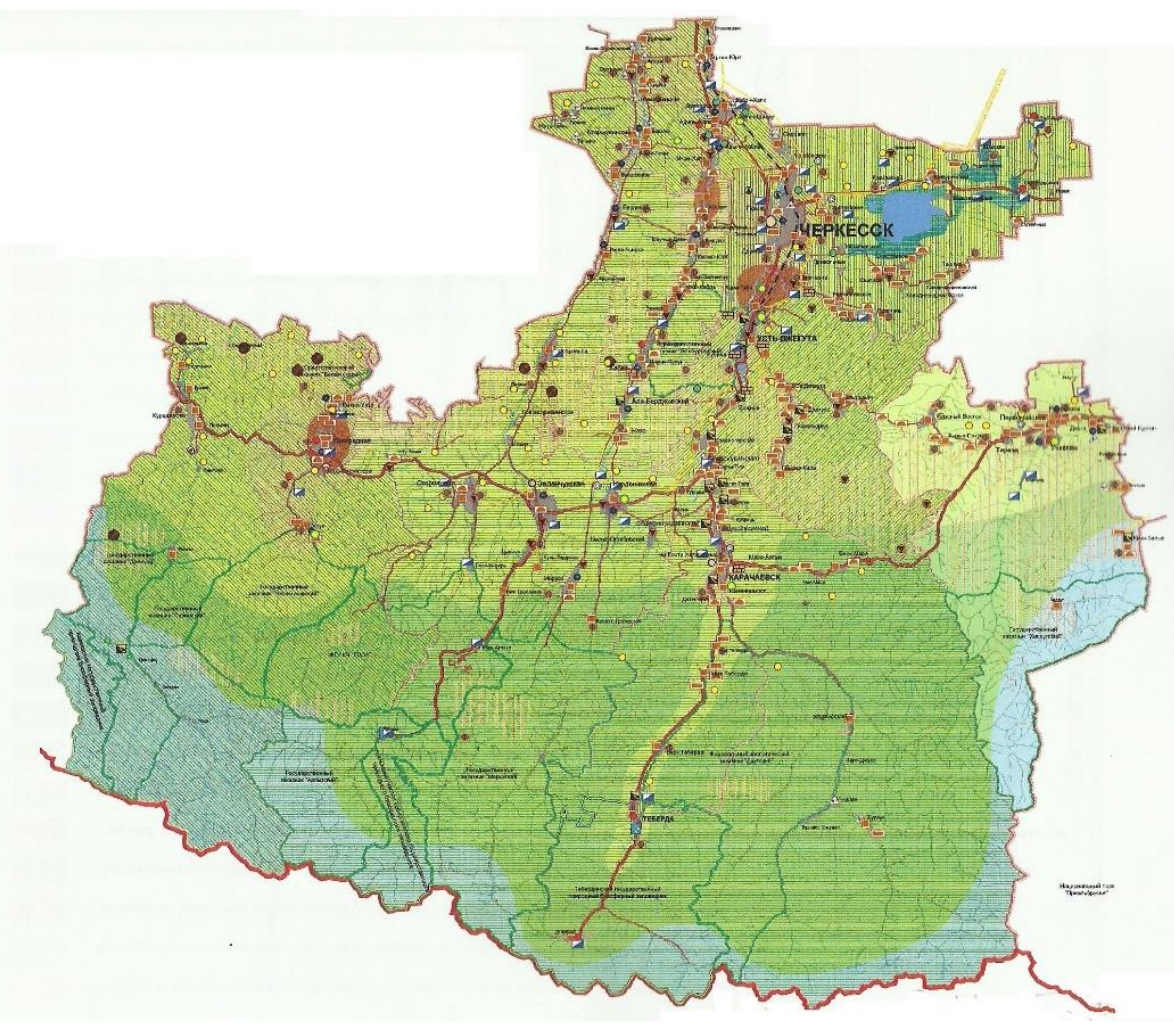

Figure 5. Integral assessment of the environmental setting in the Upper Cuban basin

\section{RESULT}

As evidenced by the economic activity aimed at utilizing water resources, for example, in the power generation at the Zelenchukskaya HPP-PSPP, the pre- and post-building phases play different roles. According to the EIA surveys in the course of building the set of hydraulic engineering structures of the Zelenchukskaya HPP-PSPP within the spatial confines of the Upper Cuban basin geosystem (Wb.g. $=113,300 \mathrm{~km}^{3}$, Wercr $=3300 \mathrm{~km}^{3}$, Fwat.terr. $=11,000 \mathrm{~km}^{2}$ ), there was no intrabasin runoff distribution in the past but there is one now and the redistributed runoff can be used to a fuller extent for power generation in the future, which stipulates the phenomenon of irretrievability (Khetsuriani et al., 2019; Bondarenko et al., 2007, 2009, 2019; Budyko \& Avakyan, 1977; Budyko \& Drozdov, 1950; Methodological Approaches to Environmental Regulation, 1996; Guidelines for Geochemical Assessment of Pollution, 1982; Guidelines for Geochemical Assessment of Surface Waters 1985; Guidelines for Geochemical Assessment of Drawing.Maps, 1998; Perelygin et al., 1987; Calculation of Emissions from Unorganized Sources in Construction Materials Industry 2001; Calculation, Regulation, and Control of Emissions of Pollutants into the Atmospheric Air 2005; Prigogine \& Nicolis, 1977; Regulation for Organizing and Carrying Out National Environmental Monitoring 2003; Chernyaev, 1999; Bondarenko et al., 2009; Mosaferi et al., 2014; Rezaeinia et al., 2018; Aazami et al., 2015) that must be considered in making the EIA of the OA as part of the NENV-OA-PPL NES.

The scientific validation of interactions in the economic activities involving the utilization of water resources is integrally related to the need for making the EIA of the operational and newly built OA in the considered NENV-OA-PPL NES. To validate the EIA methodology, we should note that the economic activity involving the utilization of water resources and the ENVS in OA influence domains are the two sides of the same coin and constitute the essence of the notion of environmental issue within the considered space and period of the basin geosystem, within which water resources are shaped and used.

The results of the comprehensive hydrochemical, atmochemical, lithochemical, and geochemical surveys of the influence domains of the OA of the Zelenchukskata HPP-PSPP within the Upper Cuban 
basin geosystem were used to identify the spatial pollution patterns in the NENV, including differentiation by environmental hazard rate.

For the generalized indicators of the environmental effects produced by the SHES of the Zelenchukskata HPP-PSPP within the Upper Cuban basin geosystem see Table 1.

Table 1. Generalized indicators of the kind of environmental effects produced by the SHES of the Zelenchukskata HPP-PSPP in the Upper Cuban basin

\begin{tabular}{|c|c|c|c|c|c|c|c|c|c|c|c|c|c|c|c|c|c|c|c|}
\hline \multirow[b]{3}{*}{$\begin{array}{l}\text { Producti } \\
\text { on } \\
\text { process }\end{array}$} & \multicolumn{19}{|c|}{ Kind of effects } \\
\hline & \multicolumn{5}{|c|}{ On natural settings } & \multicolumn{8}{|c|}{ On socioeconomic conditions } & \multicolumn{6}{|c|}{$\begin{array}{c}\text { On environmental pollution } \\
\text { level and } \\
\text { waste dumping }\end{array}$} \\
\hline & 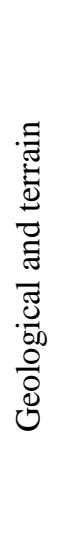 & 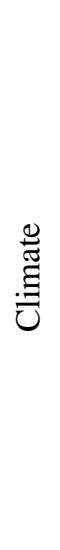 & 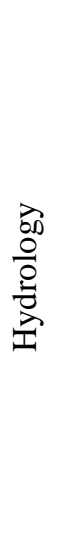 & 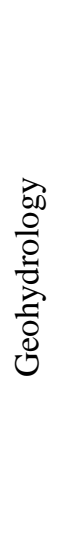 & 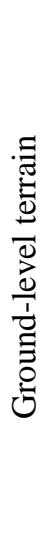 & 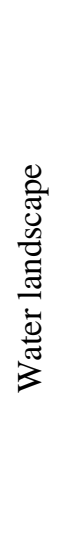 & 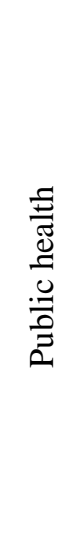 & 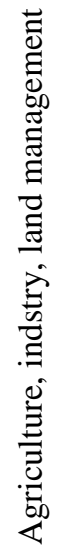 & 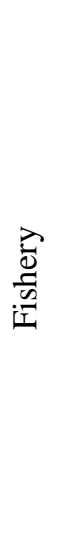 & 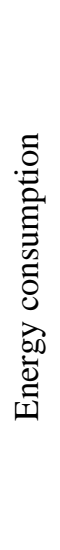 & 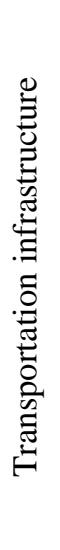 & 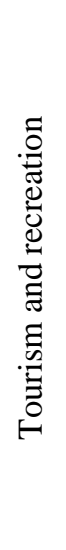 & 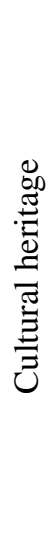 & 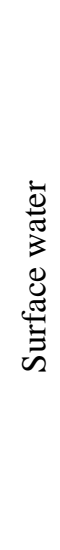 & 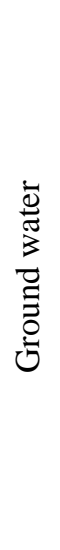 & 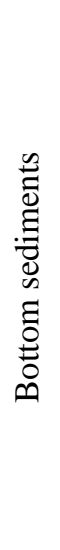 & $\begin{array}{l}\cdot \bar{\Xi} \\
\overline{0} \\
0 \\
0 \\
0 \\
0\end{array}$ & $\begin{array}{l}\overline{0} \\
\dot{0} \\
\overline{0} \\
\overline{0}\end{array}$ & 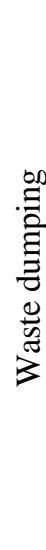 \\
\hline
\end{tabular}

In the

building

phase

In the operation $0 \quad-+$ $0 \quad 0 \quad++$ $++$ $\begin{array}{lll}0 & 0\end{array}$ $\begin{array}{lllll}0 & 0 & 0 & 0 & 0\end{array}$ 0 al phase

Note: ++ is for major positive effect; + is for minor positive effects; 0 is for effects undefined; - is for minor negative effects; -- is for major negative effects;

The methodology of validating the notion of EIA for OA by the example of the Zelenchukskata HPPPSPP located within the Upper Cuban basin geosystem and the results of the comprehensive surveys (2005-2015) of the interaction and relations among the OA, NENV, and local PPL (about 350K people) as part of the NENV-OA-PPL class of NES were used to form the methodological basics of EIA described hereinafter:

- EIA is the analysis of all real variants in adopted design solutions for constructing the SHES and the building of the HPP-PSPP on the basis of measured socioeconomic estimates;

- EIA is the form in which the customer (represented by a state-run or a joint-stock company) presents to the society the sum of conditions on which it develops the design solutions for a facility planned for construction (Zelenchukskaya HPP-PSPP); 
- EIA is one of the main ways of making an environmentally acceptable decision with the help of which the bodies of authority responsible for granting and refusing permissions would have a clear idea of all the considered variants and the consequences of their implementation.

The goal and objectives of EIA are set considering socioeconomic and environmental requirements and proceeding from the idea of EIA so as to make the PPL interested in the planned building of the OA.

The goal of EIA is to prepare environmentally sound design solutions, for example, for the building of the SHES of the Zelenchukskaya HPP-PSPP. This goal is reached by solving several problems, such as:

- identify and analyze all possible influence on the NENV in the OA influence domain in the course of building and subsequent operation;

- predict potential environmental and related socioeconomic and other effects.

According to the system approach, it is recommended to make EIA on the basis of the following principles:

- involve public organizations and the community in making decisions on (not) building OA;

- make environmental information publicly available when preparing waterworks OA building solutions;

- extend the EIA of the OA from the maiden phase of the design works up to making the final building decision;

- adhere to optionality and variability while preparing building decisions;

- elaborate the scientific rationale of potential unfavourable effects of implementing project OA building solutions;

- make the EIA in phases.

\section{DISCUSSION}

The system analysis of the interaction and relations among the NENV, OA, and PPL within the NENV-OA-PPL NES and the six general principles of the system approach to EIA are used to study the characteristics of natural (biotic and abiotic) components and socioeconomic conditions in the considered basin geosystem.

Water resources are formed and used within basin geosystems with various cubic sizes. The design parameters of these systems are defined depending on the usage goals and structural parameters of OA represented by water utilization and consumption systems. This is why, it is methodologically recommended to use the hierarchical structure of basin geosystems wih already formed networks of watercourses (big, medium, and small rivers and springs). For example, the first-level basin geosystem of river Don of 4,768,600 km in size includes more than 10,000 small and medium and several tens of big water storages, with the Tsimlyanskoe storage as the largest one in the South of Russia (its volume is $24 \mathrm{~km}^{3}$ ). Henceforth, it is methodologically expedient to consider the basin geosystem, within which water resources are formed and used in amounts sufficient for planned goals.

The utilization of water resources in various economic activity processes is stipulated by the returnable (water usage) and irretrievable (water consumption) utilization of resources and must therefore be considered in the EIA of OA. The analysis of the experience in utilizing water resources in the southern regions of Russia allows stating that the more serious is the environmental effect produced by an OA in operation, the earlier this effect should be prevented, which is why the utilization of water resources needs not so much more efficient methods of coping with negative effects as a more efficient methodology of the EIA of OA.

The purposed building of new and running of operational OA within the considered basin geosystems, proceeding from the current regulatory requirements on conserving (protecting) the NENV makes it necessary to provide ENVS within the OA influence domains by conserving a favourable living envi- 
ronment for the PPL, plants, and animals, conserving the biodiversity of ichthyofauna (fish species, etc.) and flora in the water facilities and taking other protective steps. A major environmental parameter of ENVS on operational and newly built OA is their environmental acceptability (EA) for the NENV and in the actual direct interaction with the natural environment of a water facility (NWE). Henceforth, the system approach, including the phases of design, building, and operation, is methodologically required for making environmentally sound decisions on building OA, and EIA is one of the major procedures in these decisions.

The methodology of the EIA of OA considers the system principles of interaction and relations among these objects, the structural abiotic and biotic formations of the NENV, and the vital interests of the PPL as part of the NENV-OA-PPL NES active within the spatial confines of the basin geosystem and treated as an integrated, dynamic, open, sustainably nonequilibrium system with natural and technogenic structural formations involved in continuous self-organization (Khetsuriani, Bondarenko and Yliasov 2019; Bondarenko, Yliasov and Khetsuriani 2019; Bondarenko, Privalenko, Kuvalkin et al 2009; Prigogine and Nicolis 1977; Regulation for Organizing and Carrying Out National Environmental Monitoring 2003; Chernyaev 1999; Chernyaev 1998; Guideline for Chemical Analysis...1977; Rumyantsev and Kozlov 1999; Fashchevskiy 1989; Federal Law 174-FZ On Environmental Appraisal 1995; Bondarenko, Dyachenko, Gutenev and Fedoryan 2009; Mosaferi, Pourakbar, Shakerkhatibi et al 2014; Rezaeinia, Nasseri, Binesh et al 2018; Aazami, Esmaili-Sari, Abdoli et al 2015).

In the considered EIA methodology the repercussion of empirical reality is defined by the natural condition (background reference point) of the structural formations within the basin geosystems and by the virtual changes expected in these formations as affected by the OA. When making EIA, it is important to identify the dominant transformations in the NENV-OA-PPL NES.

If natural transformations prevail over subjective ones, the NENV-OA-PPL NES will tend to follow the course of sustainable functional development. The prevalence of subjective (artificial) transformations over natural (objective) ones will stipulate the trend for increased additional technogenic loads on the NENV as part of the NENV-OA-PPL NES and, first of all, on the hydrographic fluvial network of the water catchment area, the earth crust's upper layers in the OA's active influence domains (inundated zones and coastal terrain, active filtering and waterlogging zones, etc.) within the considered basin geosystem. It should also be noted that an important part of the EIA of OA is the assessment of the NENV-OA-PPL NES for system integrity. In a self-organizing system this integrity is stipulated by the structural formations at the internal hierarchical levels.

The self-organization in nature and active NENV-OA-PPL NES is stipulated by the continuous system-level ordering and complication of structural formations and their relations among each other and with the surrounding medium. In the EIA of OA such structural formations are considered as climate, atmosphere, geological structure of the upper earth crust, plants and animals, OA as a technogenic component, operational access roads, communication systems, etc. Proceeding from the energy principle, according to which open and sustainably nonequilibrium systems run and develop, the selforganization criterion for the structural formations in NENV-OA-PPL NES is the balance ratio of free $\left(E_{\text {free }}\right)$ and bound $\left(E_{\text {bound }}\right)$ energy as related to the full energy $\left(E_{\text {full }}\right)$, coming into the system:

$$
\mathrm{E}_{\text {full }}=\mathrm{E}_{\text {free }}+\mathrm{E}_{\text {bound }}
$$

In the considered ENV-OA-PPL class of NES the prevalence of $E_{\text {free }}$, that is capable of ordering structural formations and making them more complex, over $E_{\text {bound, }}$, uncapable of doing any kind of work, forms the trend for the continuity of self-organization in the structural formations of these NES, where the natural environment continues to play the main role. The prevalence of bound (low-quality) energy of stream over $\mathrm{E}_{\text {free }}$ results in the trend for an increasing entropy within the considered ENV-OA-PPL NES and thus in a decline in functional efficiency and gradual degradation (Bondarenko, Skibin, Azarov, Semenova and Privalenko VV 2016; Bondarenko, Klimenko, Semenova and Nikolaenko 2016; Khetsuriani, Bondarenko and Yliasov 2019; Bondarenko, Yliasov and Khetsuriani 2019; Bondarenko, Privalenko, Kuvalkin et al 2009; Bondarenko, Gutenev, Privalenko and Polyakov 2007; Bondarenko, 
Privalenko, Kuvalkin et al 2009; Budyko and Avakyan 1977; Budyko and Drozdov 1950; Methodological Approaches to Environmental Regulation...1996; Chernyaev 1998; Guideline for Chemical Analysis...1977; Rumyantsev and Kozlov 1999; Fashchevskiy 1989; Federal Law 174-FZ On Environmental Appraisal 1995; Bondarenko, Dyachenko, Gutenev and Fedoryan 2009; Mosaferi, Pourakbar, Shakerkhatibi et al 2014; Rezaeinia, Nasseri, Binesh et al 2018; Aazami, Esmaili-Sari, Abdoli et al 2015). This is why, one of the main components of the methodology of the EIA of OA as part of the ENV-OA-PPL class of NES is enviromental acceptability (EA) that is a certain copy of the natural system in terms of changing forms of energy with the trend for slower entropy growth, which is ensured by the structural fineness of the building as part of the OA.

The important components of the methodology of the EIA of the OA on the NENV in the influence domains within a basin geosystem is the notion of Man and the answer to the question "What for does nature need man?" Man (population) is exactly the substance that affects its proper living environment. The quality of this environment is assessed during scientific cognition, and the results are used to improve the methods of organizing and technology of utilizing natural resources; here, we mean the limitedness of water resources that must be considered in the methodology of EIA.

\section{CONCLUSION}

As shown by analyzing the experience in utilizing water resources in the water consumption and utilization systems within the confines of the basins of rivers Cuban, Lower Don, and Terek, the more serious is the environmental effect produced by operated waterworks facilities (about 10,000) referred to as objects of activity), the earlier this effect should be prevented. It can therefore be concluded that the utilization of water resources needs not so much more efficient methods of coping with negative effects as a more efficient methodology of environmental impact assessment (EIA) of operational and newly created OA.

\section{REFERENCES}

Aazami, J, Esmaili-Sari, A, Abdoli, A., Sohrabi, H., \& Van den Brink, P. .J. (2015). Monitoring and assessment of water health quality in the Tajan River, Iran using physicochemical, fish and macroinvertebrates indices. Journal of Environmental Health Science and Engineering, 13, 29.

Bondarenko, V.L., Dyachenko, V.B., Gutenev, V.V. \& Fedoryan, A.V. (2009). Energy-Entropy Approach to Environmental Economic Feasibility Study of Building and Reconstructing Reservoir Hydrosystems. Ecology of Urban Territory, 1, 6-10.

o

Bondarenko, V.L., Gutenev, V.V., Privalenko, V.V., \& Polyakov, E.S. (2007). Environmental impact assessment (EIA) in the design of the water management complex of the Zelenchukskaya HPP. Theoretical and applied ecology, 1, 47-54.

Bondarenko, V.L., Klimenko, O.V., Semenova, E.A., \& Nikolaenko, D.A. (2016). Environmental Safety in Construction. Engineering and Environmental Survey As Part of Set of Surveys for Building Waterworks Facilities. Novocherkassk: Novocherkassk Engineering and Land Reclamation Institute, Don State Agrarian University.

Bondarenko, V.L., Privalenko, V.V., Kuvalkin, A.V. (2009a). Resolving Environmental Issues When Designing Hydraulic Engineering Structures by the Example of the Upper Cuban Basin Geosystem. Rostov-on-Don: Southern Scientific Centre of the Russian Academy of Sciences.

Bondarenko, V.L., Skibin, G.M., Azarov, V.N., Semenova, E.A. \& Privalenko, V.V. (2016). Environmental Safety in Nature Management, Water Use, and Construction: Assessing Environmental State of Basin Geosystems. Novocherkassk: M. I. Platov South Russian state Polytechnic University (NPI). 
Bondarenko, V.L., Yliasov, A.I. and Khetsuriani, E.D. (2019). Scientific and Methodological Basics of Natural Engineering Systems for Utilizing Water Resources by the Example of Basin Geosystem Territories. Novocherkassk: Novocherkassk Engineering and Land Reclamation Institute; M. I. Platov South Russian state Polytechnic University (NPI).

Budyko, M.I., \& Avakyan, A.B. (1977). Global Ecology. Moscow: Mysl.

Budyko, M.I., \& Drozdov, O.A. (1950). On Hydrological Cycle in Limited Land Area. In: Hydrometeorological Efficiency of Field-Protective Forestation. Leningrad: Gidrometeoizdat,.

Chernyaev, A.M. (1999). River Basins. Agroekologiya Publishers of the Federal Water Resources Agency, Yekaterinburg.

Chernyaev, A.M. (1998). Water Resource Potential of Russia. Agroekologiya Publishers of the Federal Water Resources Agency, Yekaterinburg.

Calculation of Emissions from Unorganized Sources in Construction Materials Industry: Study Guide (2001). Novorossiysk: ZAO NIPIOTSTROM.

Calculation, Regulation, and Control of Emissions of Pollutants into the Atmospheric Air: Study Guide (2005). OAO Atmosphere Research Institute, Saint-Petersburg.

Fashchevskiy, B.V. (1989). Environmental Validation of Permisssible River Runoff Regulation Rate. Series 87.19.91. Environmental Conservation. Central Research Institute for Complex Use of Water Resources, Minsk.

On Environmental Appraisal (1995). Federal Law 174-FZ (As Amended of 30 December 2020). https://docs.cntd.ru/document/9014668

Semenov A.D. (ed.). (1977). Guideline for Chemical Analysis of Dry Land Surface Waters. Leningrad: Gidrometeoizdat.

Guidelines for Geochemical Assessment of Pollution of Urban Territories with Chemical Elements (1982). Moscow: Institute of Mineralogy, Geochemistry, and Crystal Chemistry of Rare Earth Elements.

Guidelines for Geochemical Assessment of Surface Waters (1985). Moscow: Institute of Mineralogy, Geochemistry, and Crystal Chemistry of Rare Earth Elements.

Guidelines for Geochemical Assessment of Drawing 1:200,000 -1:100,000 Environmental and Geological Maps (1998). Moscow: All-Russian Scientific and Research Institute of Hydrogeology and Engineering Geology.

Khetsuriani, E.D., Bondarenko, V.L., Klimenko, O.V., and Semenova, E.A. (2019a). Methodological measurement basis environmental safety in construction and operation of water management facilities. In: Proceedings of the International Conference on Modern Trends in Manufacturing Technologies and Equipment (ICMTMTE). https://www.e3sconferences.org/articles/e3sconf/pdf/2019/52/e3sconf_icmtmte2019_00066.pdf

Khetsuriani, E.D., Bondarenko, V.L., Yliasov, A.I., and Semenova, E.A. (2019b). Evaluation of environmental safety of waterworks for urban water supply systems. In: Proceedings of the International Scientific Conference Construction and Architecture: Theory and Practice of Innovative Development, IOP Conference Series: Materials Science and Engineering. https://iopscience.iop.org/article/10.1088/1757-899X/698/7/077060 
Khetsuriani, E.D., Bondarenko, V.L., \& Yliasov, A.I. (2019c). Methodological Framework for the Assessment of the Zones of Influence of Technological Water Systems Multipurpose Water Supply Urban Households and the Economy. Biosphere compatibility: human, region, technologies, 4 (28), 25-35.

Methodological Approaches to Environmental Regulation of Anthropogenic Reduction in River Runoff (1996). Water Resours, 1: 78-85.

Mosaferi, M., Pourakbar, M., Shakerkhatibi, M. et al. (2014). Quality modeling of drinking groundwater using GIS in rural communities, northwest of Iran. Journal of Environmental Health Science and Engineering volume 12, 99. doi: 10.1186/2052-336X-12-99

Perelygin, V.M., Tonkopii, N.I., Pertsovskaya, A.F., Pavlov, V.N., Grigoyeva, T.I., Shestopalova, G.E. (1987). Guidelines for Assessing Hazard Rate of Soil Pollution with Chemical Elements. Moscow: Sysin Institute of General and Communal Hygiene of the U.S.S.R. Academy of Medicine.

Nicolis, G., Prigogine, I. (1977). Self-Organization in Nonequilibrium Systems: From Dissipative Structures to Order through Fluctuations. John Wiley and Son: New York, NY, USA, 197

Regulation for Organizing and Carrying Out National Environmental Monitoring (2003). Adopted by Russian Government Decree 77 of March 31. http://www.consultant.ru/search/

Rezaeinia, S., Nasseri, S., Binesh, M. et al. (2018). Qualitative and health-related evaluation of pointof-use water treatment equipment performance in three cities of Iran. J Environ Health Sci Eng, 16(2), $265-275$.

Rumyantsev, I.S., and Kozlov, D.V. (1999). Environmental Problems of Russia's Water Reservoirs and Constructional Hydroecology. Gidrotekhnicheskoye stroitel'stvo (Hydraulic engineering), 6, 53-54

\section{SEMBLANCE OF THE AUTHORS}

Vladimir L. Bondarenko: He is a Doctor of Technical Sciences, Professor of the Department of Technosphere safety, land reclamation and environmental management» at Novocherkassk Engineering and Land Reclamation Institute Of Don State Agrarian University. His areas of research interest include development and improvement of environmentally acceptable structures of hydraulic structures, creation and development of the foundations of the technical theory of natural and technical systems (PTS) "Natural environment - Object of activity - Population ("PS-O.D.N. ")" on the use of water resources in the branches of economic activity

Elguja D. Khetsuriani: $\mathrm{He}$ is a $\mathrm{PhD}$ in Technical Sciences, docent, professor of the Department "Water management, engineering networks and environmental protection", M. I. Platov South Russian state Polytechnic University (NPI), Associate Professor of the Department "Technical means of aquaculture", Don state technical University. His areas of research interest include development and improvement of environmentally friendly structures of hydraulic structures, environmental safety in the use of water resources, environmental water use and high-quality water supply.

Allaberdy. I. Yliasov: He is a Doctor of Technical Sciences, Professor, Director of the WTL (USA) branch in Asia. His areas of research interest include development and improvement of the technology for the production of needle-shaped coke and products of processing of Turkmen oil, in co-authorship the monograph "Physicochemical laws of thermolysis of complex hydrocarbon systems: experiment, theory, technology, creation and development of the methodology of the class of natural and technical systems (PTS)" Natural environment Object activities - Population ("PS-O.D.-N.") "on the use of water resources in various types of economic activities, including the oil refining industry.

Elena. A. Semenova: She is a Docent, Candidate of technical Sciences, Dean Of the school of Caucasian hospitality of the branch of the North Caucasus Federal University. Her fields of scientific interests include environmental safety in the use of water resources, the creation and development of the foundations of the technical theory of natural and technical systems (PTS) "Natural environment - Object of activity - Population (" PS- 
O.D.N. ")" on the use of water resources in branches of economic activity - systems of multipurpose water supply of municipalities, fuel for power facilities of CHP, GRES, NPP, HPP-NPP and others, improvement of layouts of dedusting systems for localized ventilation in lime production.

Valery N. Azarov: He is a Doctor of Technical Sciences, Professor, Head of the Department "life Safety in construction and urban economy", Honored ecologist of the Russian Federation, Winner of the Russian government prize in the field of education, adviser to the RAASN. His areas of research interest include areas of increasing the efficiency of environmental systems, improving dust and gas cleaning devices and devices, improving the waste management system, developing technologies for waste processing, researching the dispersed composition of dust. 